\title{
Exploring flexibility of aggregated residential electric heat pumps
}

DOI:

10.1109/ENERGYCON.2016.7514082

\section{Document Version}

Accepted author manuscript

Link to publication record in Manchester Research Explorer

\section{Citation for published version (APA):}

Chapman, N., Zhang, L., Good, N., \& Mancarella, P. (2016). Exploring flexibility of aggregated residential electric heat pumps. In 2016 IEEE International Energy Conference, ENERGYCON 2016 [7514082] IEEE.

https://doi.org/10.1109/ENERGYCON.2016.7514082

\section{Published in:}

2016 IEEE International Energy Conference, ENERGYCON 2016

\section{Citing this paper}

Please note that where the full-text provided on Manchester Research Explorer is the Author Accepted Manuscript or Proof version this may differ from the final Published version. If citing, it is advised that you check and use the publisher's definitive version.

\section{General rights}

Copyright and moral rights for the publications made accessible in the Research Explorer are retained by the authors and/or other copyright owners and it is a condition of accessing publications that users recognise and abide by the legal requirements associated with these rights.

\section{Takedown policy}

If you believe that this document breaches copyright please refer to the University of Manchester's Takedown Procedures [http://man.ac.uk/04Y6Bo] or contact uml.scholarlycommunications@manchester.ac.uk providing relevant details, so we can investigate your claim.

\section{OPEN ACCESS}




\title{
Exploring Flexibility of Aggregated Residential Electric Heat Pumps
}

\author{
Nick Chapman ${ }^{1}$,Lingxi Zhang ${ }^{2}$, Nicholas Good ${ }^{3}$, Pierluigi Mancarella ${ }^{4}$ \\ School of Electrical and Electronic Engineering, University of Manchester \\ Manchester, United Kingdom \\ ${ }^{1}$ nick.chapman@ postgrad.manchester.ac.uk, ${ }^{2}$ lingxi.zhang@ @ostgrad.manchester.ac.uk, \\ 3nicholas.good@manchester.ac.uk, ${ }^{4}$ p.mancarella@manchester.ac.uk
}

\begin{abstract}
The integration of Renewable Energy Sources (RES) and the electrification of the heating and transportation sectors are stressing the operation of current power systems and call for more flexibility. Domestic electric heat pumps (EHP), which are expected to be widely deployed in the future, can be considered as one potential source of such system flexibility. However, this can also lead to negative impacts for building occupant comfort and to increased peak demand, through reduction in load diversity. Such impacts may be mitigated through the deployment of Thermal Energy Storage (TES), although the benefit this brings is not well understood. Therefore, this paper presents a method to quantify the impact on occupant comfort level and load diversity, through various payback metrics. A validated model is then used to simulate the extraction of reserve capacity from a cluster of $\mathbf{5 0 0}$ domestic buildings with EHPs and different configurations of space heating buffer. Performance in terms of occupant comfort and payback is evaluated.
\end{abstract}

Index Terms - Demand Response, Electric Heat Pump, Virtual Power Plant, Renewable Energy Resources.

\section{INTRODUCTION}

In order to decelerate global warming national governments have set different decarbonisation targets to replace fossil fuels with "green" energy resources. Increasing the penetration level of Renewable Energy Sources (RES), such as wind and solar, is an effective method to reduce the carbon emissions of current power systems. However, due to the uncertainty of renewable energy generation, a more flexible system is required to accommodate RES whilst ensuring system security. This may substantially change the traditional power system operating principle of "generation following demand" to "demand following generation" [1]. On the other hand, the upcoming electrification in the heating and transportation sectors will increase the peak demand of the system, which may aggravate the shortage of flexibility as this can increase the gap between the renewable generation and the electrical demand.

Although the two transformations mentioned above seem to simultaneously increase the demand and reduce the supply of flexibility, there is also some potential for increased flexibility to be explored. One of the characteristics of domestic heating demand is its flexibility, as the thermal inertia of buildings can help to shift the thermal demand without major impact on occupant comfort level. Therefore, it is viable to establish some control mechanisms on the ElectroThermal Technologies (ETT) operation, which is commonly recognised as one type of Demand Response (DR). Examples of using control of a single ETT to increase the flexibility are given in [2], [3]. However, the potential flexibility of a single unit is too small to be efficiently exploited, due to its limited power rating. To more efficiently exploit flexibility, resources can be aggregated by forming a Virtual Power Plant (VPP). In [4], a method for quantifying the flexibility of aggregated ETTs is introduced, and a model is used to validate the method. However, the modelling of thermal losses and heating units is simplified due to lack of sufficient consideration of the interactions between different components of the heat distribution system. To improve upon the method utilised in [4], it is necessary to choose a domestic energy consumption model, which has the features of physical modelling. Such a model is employed in this work, allowing for accurate consideration of the effect of building, heating system and heat storage thermal inertia. Further, the physical basis enables consideration of occupant thermal comfort; an important aspect not appreciated widely in the literature. Additionally, the side effect of using a heat pump cluster to provide reserve, which will result in load shifting, which can stress the operation of distribution network, has been rarely recognised. This effect can be material, as demonstrated in [5] where the impact of coupling a buffer with a heat pump to achieve load shifting is discussed. It is found that the operation of different dwellings' heat pumps is synchronised and causes a much higher peak than in the normal operation case. Therefore, it is necessary to have a detailed simulation of the cluster's behaviour in order to offer insight on the after effect of the reserve provision, such as the short term peak increase and energy consumption recovery, which can heavily impact operation of the distribution network.

The aim of this paper is to give analyses of the flexibility of an EHP cluster. The impact of EHP curtailment on social and physical aspects, such as occupant comfort and peak load, is considered, with particular focus on the effect of integrating additional TES. 
The remainder of the paper is organised as follows. Section II introduces a methodology used to model the physical system and quantify thermal comfort and payback impacts. Section III describes the characteristics of the chosen case study and Section IV comprises the results and analysis of this system. Finally, Section V provides a conclusion and recommendations for further work.

\section{Methodology}

\section{A. Domestic energy consumption model}

In order to simulate energy consumption and temperature of a cluster of houses at high resolution and granularity, a domestic energy consumption model, as introduced in [6][10], is selected. The model is composed of physically-based energy-consumption modules, incorporating space heating, domestic hot water (DHW), and cooking models. Space heating demand is determined using an electrical analogue model with four nodes, as described in [10]. These nodes represent the key components of a typical UK domestic dwelling: indoor environment (such as air and furniture), internal wall, inner and outer parts of external wall. In addition, the underfloor heating system is also modelled as a two node electrical analogue, which represents the thermal capacities of the water circulated in the underfloor pipes and the floor itself. Using this model a thermal demand profile is generated with one-minute resolution. Such a resolution can be considered necessary for modelling secondary control system reserve provision, as mentioned in [11].

\section{1) Heating system configurations}

The schematic diagram of the heating system simulated here is shown in Error! Reference source not found.. The system is designed such that the heat supply is guaranteed to meet the space heating demand and DHW demand, through underfloor heating and the DHW tank respectively. Also, an additional buffer for space heating supply can be added to increase the thermal inertia of the emitter and reduce the cycling of the heating units.

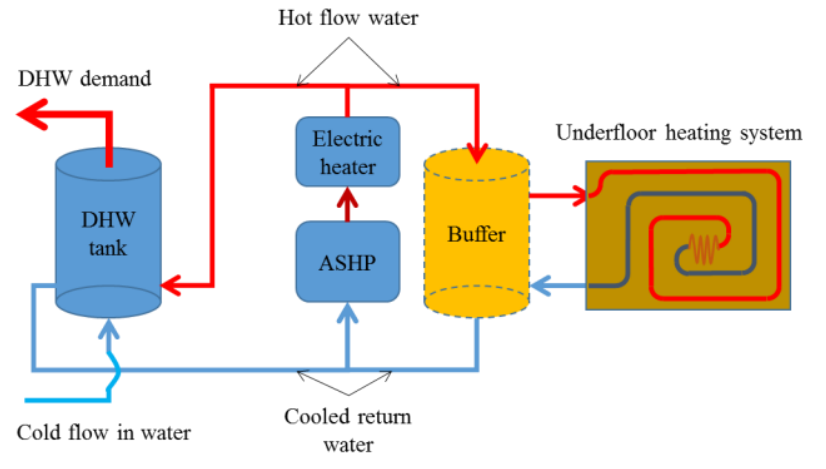

Figure 1. Schematic diagram of heating system

\section{2) EHP model}

The modelling method for the heating unit analysed here (EHP) is specified in the following section. The heat generation of an EHP $\left(H^{n, t}\right)$ is dependent on several factors: the operational states of $\operatorname{EHP}\left(u_{E H P}^{n, t}\right)$, the coefficient of performance $\left(\operatorname{COP}_{T_{s}^{n, t}, T_{r}^{n, t}}^{n, t}\right)$ and the input electrical power $\left(P_{T_{r}^{n, t}}^{n, t}\right)$. The operational state of EHP is a binary value determined by the temperature level of the DHW tank, emitter or buffer. If the temperature of DHW tank and/or buffer (emitter for non-buffer case) reaches the higher/lower level of the target hysteresis range, the EHP is turned off/on. As described in [12], the COP of EHP is determined by the temperature of the return water from heating system $\left(T_{r}^{t}\right)$ and the source temperature $\left(T_{s}^{t}\right)$. The source could be air, ground and water (for air source heat pump (ASHP), ground source heat pump and water source heat pump, respectively). The input electrical power varies with the return temperature, following the test under standard BS EN 14511 [13]. The input electrical power reduces with a lower return temperature, as shown in [14]. This is because a lower return temperature results a higher COP given the same source temperature, which results in a lower electrical input power. In addition, heat generation is limited by the maximum heat capacity of the water, which is calculated with the maximum flow water temperature $\left(T_{f}^{\max }\right)$, the temperature of the return water from the heating system, the specific heat capacity of the water $\left(c_{w}\right)$ and mass of flow water $(\dot{m})$, as shown in (1).

$$
H^{n, t}=\min \left\{u_{E H P}^{n, t} \cdot P_{T_{r}^{n, t}}^{n, t} \cdot C O P_{T_{s}^{n, t}, T_{r}^{n, t}}^{n, t},\left(T_{f}^{\max }-T_{r}^{n, t}\right) c_{w} \dot{m}\right\}
$$

\section{3) Demand response mechanism}

The DR activity introduced in this paper is achieved by altering the operational schedule of the EHPs, as shown in Figure 2. For example, in the provision of upward reserve case, the total demand of EHP ( $E_{\text {baseline }}^{t}$ ) in the normal operational case is aimed to be reduced by a specific reserve capacity $(R)$ throughout the reserve period. Moreover, the comfort level of consumers is taken into account. In order to minimise the impact of DR on the consumers within the cluster, the dwellings are ranked by comparing their indoor temperatures $\left(T_{i n}^{n, t}\right)$ with each other. Then the EHPs of dwellings with higher indoor temperature are compulsorily switched off until the demand reduction reached the reserve requirement amount. Although, it needs to be mentioned that all the EHPs are deactivated when reserve requirement is equal or higher than the baseline demand.

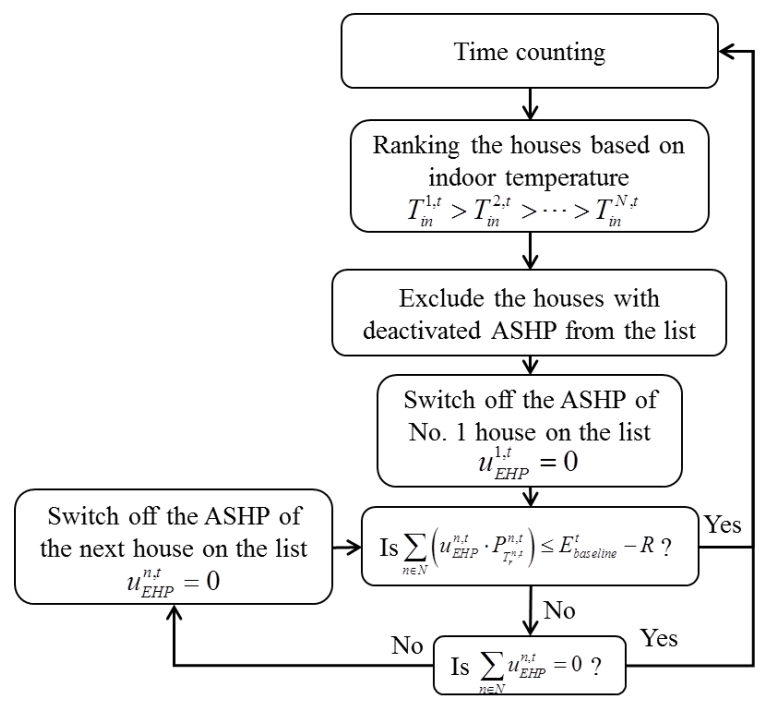

Figure 2. Demand response mechanism flow chart 


\section{B. Assessment of Flexibility Impact}

\section{1) Payback}

Three metrics have been used to quantify payback. All are based the increase in power following a DR event, rather than the more familiar 'energy payback' metric [16]. Power payback is of particular interest to distribution network operators, since increase in power consumption may lead to voltage and thermal problems.

Firstly, 'power payback' is defined as the maximum increase in aggregated power $\left(P_{D R}\right)$ following the reserve period relative to baseline power $\left(P_{\text {baseline }}\right)$ during the same period. The period over which payback is considered begins immediately after the reserve period ends (at $t_{\text {end }}$ ) and lasts for the same duration as the reserve period (until $\left.t_{\text {end }+ \text { duration }}\right)$, as formalised in Equation 2 below.

$$
\begin{gathered}
\text { Power Payback }=\operatorname{Max}\left(P_{D R}(t)-P_{\text {baseline }}(t)\right) \\
\text { for } t \in\left(t_{\text {end }}, t_{\text {end }+ \text { duration }}\right]
\end{gathered}
$$

Secondly, payback is expressed as a 'percentage of the reserve capacity $\left(P_{R}\right)$ ' provided by the cluster. This metric allows payback to be generalised, and captures the relationship between reserve capacity and power payback. Equation 3 below describes this metric.

$$
\% \text { Reserve Capacity }=\frac{\text { Power } \text { Payback }}{P_{R}}
$$

Finally, the paper quantifies payback as a 'percentage increase in daily peak load', as given in Equation 4 below. This information is of interest to network operators with networks operating close to capacity.

$$
\begin{array}{r}
\% \text { Peak }=\frac{\operatorname{Max}\left(P_{D R}(t)\right)-\operatorname{Max}\left(P_{\text {base }}(t)\right)}{\operatorname{Max}\left(P_{\text {base }}(t)\right)} \\
\text { for } t \in(0,1440)
\end{array}
$$

\section{2) Comfort}

Comfort is characterised as the deviation in inside temperature from the baseline during and after EHP curtailment. In the paper, comfort is considered both in terms of the mean average temperature deviation experienced by the cluster, as well as in terms of the number of customers that experience a temperature deviation greater than a pre-defined threshold. Assessing the number of customers affected in this way is important to understanding the distribution of comfort impacts across the cluster.

\section{CASE STUDY}

A cluster of 500 modern semi-detached houses (built between 1944 and 1984), each with $96 \mathrm{~m}^{2}$ floor area, has been chosen as a representative group for modelling the VPP. Space heating and DHW demands are supplied to all properties by ASHP units, with an aggregated power rating of $881 \mathrm{~kW}$ $(1.76 \mathrm{~kW}$ average per property). Underfloor heating is chosen for the heat delivery system, since underfloor heating has been shown to perform better than radiators in terms of EHP efficiency [17] and impact on the Low Voltage (LV) network [6]. Indoor set temperature is $21^{\circ} \mathrm{C}$ during periods of active occupancy and $15^{\circ} \mathrm{C}$ otherwise, with $0.5^{\circ} \mathrm{C}$ dead-band either side of the set and set-back temperatures. For cases with a space-heating buffer, water is maintained between $48^{\circ} \mathrm{C}$ and $55^{\circ} \mathrm{C}$ by the ASHP.

The study is carried out for an extremely cold winter day in the North-West of the UK, with an average temperature of $-2.8^{\circ} \mathrm{C}$ and temperature range between $-5^{\circ} \mathrm{C}$ and $0.1^{\circ} \mathrm{C}$. Under such conditions, the impact of EHP curtailment is likely to be greatest in terms of network stress and customer comfort. The cluster is instructed to provide upward reserve capacity (load reduction) between the hours of 18:00 - 19:00 by curtailing ASHP units according to the control strategy described in the methodology. The scheduling and duration of reserve reflects typical reserve markets in the UK, such as Short Term Operating Reserve (STOR) and Demand Side Balancing Reserve (DSBR). However, due to the computational burden of modelling more than 500 houses, the reserve capacities modelled fall short of the minimum requirements for both these markets. Results may nonetheless be scaled up to large cluster sizes due to the coincidence factor for 500 houses being near its asymptotic maximum [10].

The model is run in MATLAB R2014a on a computer with 16GB RAM and $2.3 \mathrm{GHz}$ processer, and takes 163 minutes to simulate three days of baseline conditions at one minute resolution. The reason of running a three days simulation is because the first day is used to preheat all the components to reach stable states, then DR activity is simulated in the second day and the last day is for researching the impacts following DR. A further 97 minutes are required to run the model a second time for the DR case. The time is reduced since the DR case is equal to the base time up until the EHP curtailment first occurs.

\section{RESULTS}

Results from the case study modelling are presented in the following two subsections. The first subsection, Reserve Capacity Analysis', compares different reserve capacities with and without the presence of a 300 litre space-heating buffer. The second subsection, 'Buffer Volume Analysis', compares different space-heating buffer volumes with a fixed $500 \mathrm{~kW}$ reserve capacity. Both studies are assessed in terms of the impact ASHP curtailment has on the cluster's peak electricity consumption (power payback) and consumer comfort. These two impacts are quantified by comparing the load and inside temperature for DR test cases against the baseline case without DR.

\section{A. Resever Capacity Analysis}

\section{1) Payback}

Figure 3Error! Reference source not found. shows the cluster's aggregated load relative to the baseline for different reserve capacities $(250 \mathrm{~kW}, 500 \mathrm{~kW}$ and $1000 \mathrm{~kW})$ with and without a 3001 space-heating buffer. It can be seen that the cluster successfully delivers $250 \mathrm{~kW}$ and $500 \mathrm{~kW}$ reserve capacity but is unable to deliver the full $1000 \mathrm{~kW}$ reserve capacity, since the total active ASHP load is less than $1000 \mathrm{~kW}$ during the reserve period. For the $1000 \mathrm{~kW}$ buffer and nonbuffer cases $859 \mathrm{~kW}$ and $767 \mathrm{~kW}$ reserve are delivered on average respectively. The difference in these quantities indicates that the baseline ASHP load is greater during the reserve period when the buffer was present. 
Following the ASHP curtailment period there is a small amount of power payback across all cases, represented by a positive relative electricity consumption. As described in the methodology section, Table I quantifies 'power payback', 'power payback as a percentage of reserve capacity' and 'percentage increase in daily peak load'. Power payback is relatively small, varying from between $7 \%$ to $15 \%$ of the reserve capacity across all cases. The limited level of power payback is primarily due to the extreme cold conditions and the scheduling of the reserve period, which means that baseline ASHP load is already near the maximum ASHP capacity immediately after the reserve period (i.e. the diversity factor is near 1). Increase in daily peak load also increases between $0 \%$ and $7 \%$, which could negatively affect LV networks operating near capacity. It is worth recognising that the daily peak load in this case study is likely to be equal to the annual peak load due to the extreme cold conditions.

Results also indicate that power payback increases with reserve capacity for both buffer and non-buffer cases. This is principally because an increase in reserve capacity causes the inside temperature (and buffer temperature) of more houses to fall below the minimum dead-band temperature during the reserve period. This causes a greater number of ASHPs to become synchronised once the reserve period finishes and a larger power peak can be seen as a result. Finally, the results suggest that the presence of the buffer reduces power payback as a percentage of the reserve capacity by approximately $4 \%$. This is due to the buffer reducing the number of houses that fall below the dead-band temperature during the reserve periods, thus reducing the number of ASHPs to be activated immediately after the reserve period.

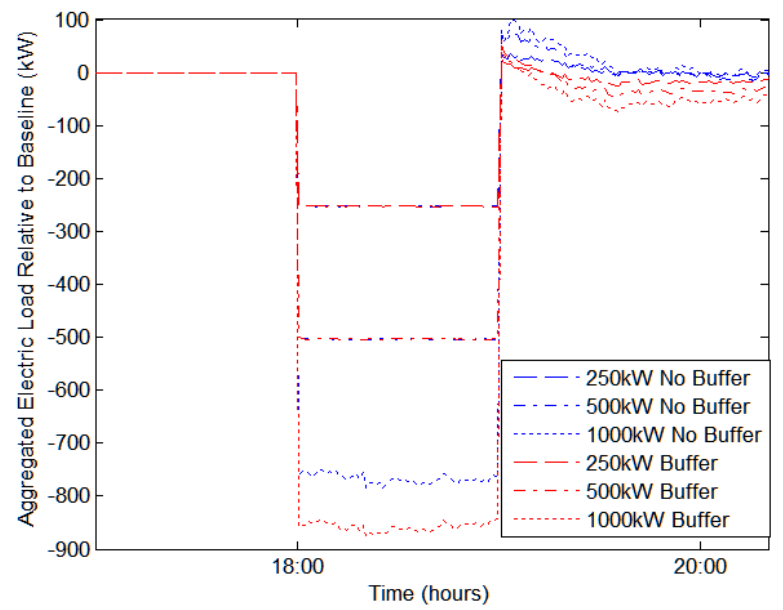

Figure 3. Aggregated electric load relative to the baseline vs time

TABLE I. PAYBACK - RESERVE CAPACITY ANALYSIS

\begin{tabular}{|c|c|c|c|c|}
\hline $\begin{array}{c}\text { Reserve } \\
\text { Volume } \\
(\mathbf{k W})\end{array}$ & Buffer & $\begin{array}{c}\text { Power } \\
\text { Payback } \\
(\mathbf{k W})\end{array}$ & $\begin{array}{c}\text { Power Payback } \\
\text { as a Percentage of } \\
\text { Reserve Capacity } \\
(\boldsymbol{\%})\end{array}$ & $\begin{array}{c}\text { Percentage } \\
\text { Increase in Daily } \\
\text { Peak Load (\%) }\end{array}$ \\
\hline 250 & No & 35.9 & $14 \%$ & $2 \%$ \\
\hline 250 & Yes & 26.1 & $10 \%$ & $0 \%$ \\
\hline 500 & No & 76.3 & $15 \%$ & $5 \%$ \\
\hline 500 & Yes & 53.1 & $11 \%$ & $2 \%$ \\
\hline 767 & No & 99.3 & $13 \%$ & $7 \%$ \\
\hline 859 & Yes & 58.8 & $7 \%$ & $2 \%$ \\
\hline
\end{tabular}

\section{2) Comfort}

Figure 4 illustrates the mean average inside air temperature relative to the baseline across all houses in the portfolio. It can be observed that indoor temperature reduces significantly due to ASHP curtailment and the extreme cold conditions. The addition of the buffer reduces the maximum average temperature drop by between $37 \%$ and $41 \%$ across all reserve capacities. This is primarily because the buffers can supply heat to the building whilst the ASHP units are curtailed.

Figure 5 shows the number of houses with inside air temperature relative to the baseline less than $-0.5^{\circ} \mathrm{C}$. This graph shows that for all buffer cases no customers exceed this temperature range. On the other hand, for cases without a buffer, the percentage of houses exceeding this limit can reach $24 \%, 49 \%$ and $79 \%$ for the $250 \mathrm{~kW}, 500 \mathrm{~kW}$ and $1000 \mathrm{~kW}$ cases respectively. These percentages are much greater than what would be expected if all house temperatures relative to the baseline were evenly distributed either side of the mean average (based on Figure 4). This suggests that a large proportion of houses fall just below the mean, whilst a small proportion fall significantly above the mean. This distribution occurs principally because, although all houses tend to experience a similar relative comfort loss during the reserve period, only a small proportion end the reserve period with their temperature below the minimum dead-band level namely those that began the reserve period with their inside temperature close to the lower dead-band limit. This means that only a small number of ASHP units are reactivated immediately after the reserve period and consequently only a small number houses recover their comfort level. For all remaining houses, the relative temperatures continue on a similar downwards trajectory following the reserve period until the lower dead-band limit is exceeded. This leads to a highly concentrated number of houses with relative inside temperature just below the mean average following the reserve period.

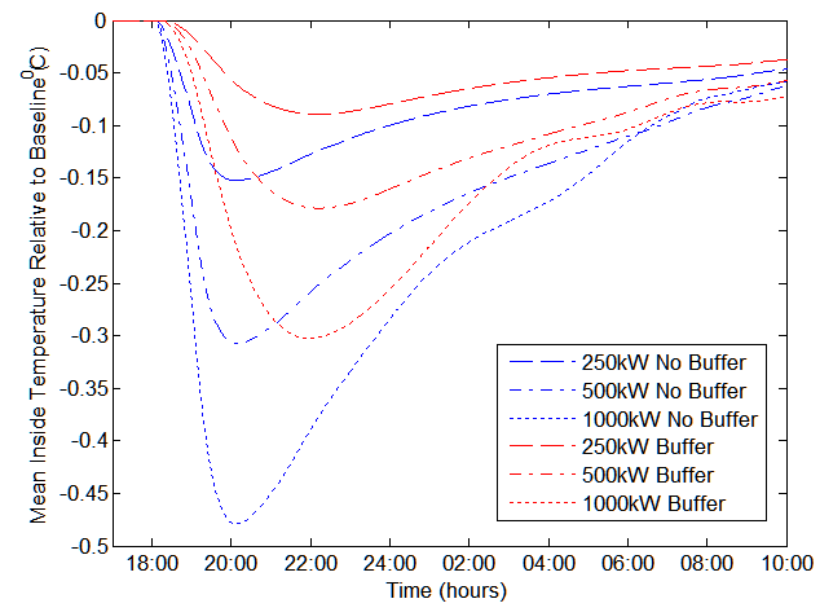

Figure 4. Mean inside temperature relative to the baseline vs time 


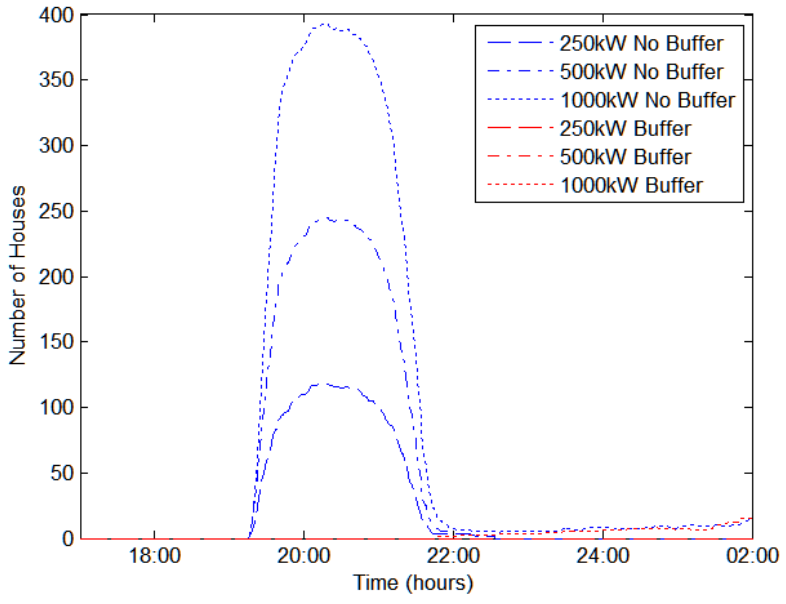

Figure 5. Number of houses with inside temperature relative to the baseline below $-0.5^{\circ} \mathrm{C}$ vs time

\section{B. Buffer Volume Analysis}

\section{1) Payback}

Figure 6 shows the aggregated load profile relative to the baseline for cases with different buffer volumes (no buffer, $1501,3001,6001)$ providing $500 \mathrm{~kW}$ reserve capacity. It is also possible to see a small power payback for all cases following the reserve period. Table II quantifies payback according to the same three indicators as in the previous section. Like the previous analysis, greatest power payback is exhibited by the case with no buffer present. As before, this is caused by a greater number of houses dropping below the dead-band temperature during the reserve period compared with the buffer cases. Regarding peak load of the cluster, results indicate a small increase in daily peak load of $5 \%$ for the no buffer case and between $1 \%$ and $3 \%$ for the buffer cases. Note that results in the $1^{\text {st }}$ and $3^{\text {rd }}$ rows of Table II are equal to the results in the $3^{\text {rd }}$ and $4^{\text {th }}$ rows of Table I respectively.

Rather counterintuitively, cases with larger volume buffers have slightly greater power payback than cases with smaller volume buffers. For example, power payback increases by about $10 \mathrm{~kW}$ each time a larger buffer is modelled. Larger buffers cause additional payback principally because the water temperature inside the buffer reduces less during the reserve period compared with smaller buffer cases. This means that for larger buffer cases the return flow temperature to the ASHP is comparatively high following the reserve period, causing the ASHP to operate with a lower COP. Since the COP is lower for cases with larger buffers the ASHP electric load is great, leading to greater payback. The COP of the four cases immediately following the reserve period is shown in Figure 7. This explanation demonstrates the benefit of using a detailed physical model to capture the behaviour of all elements of the heating system at high resolution.

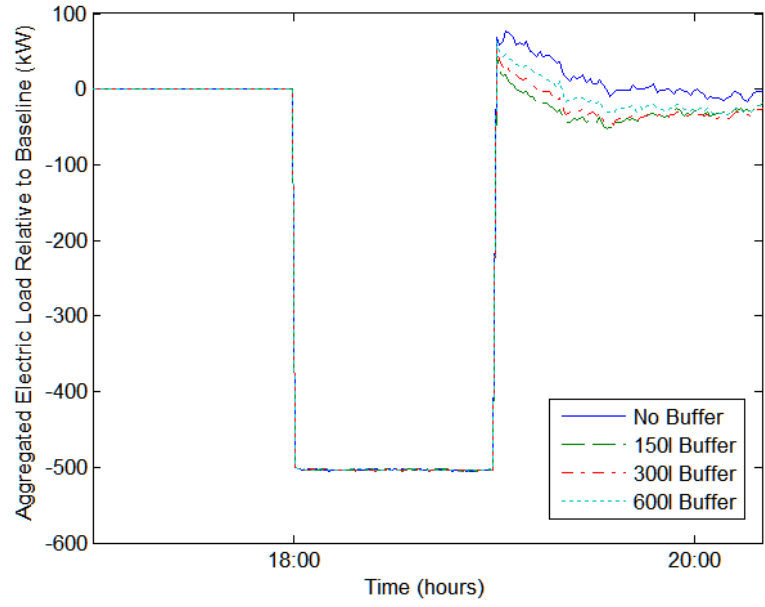

Figure 6. Aggregated electric load relative to the baseline vs time

TABLE II. PAYBACK - BUfFER VOLUME ANALYSIS

\begin{tabular}{|c|c|c|c|}
\hline $\begin{array}{c}\text { Buffer } \\
\text { Volume } \\
\text { (litres) }\end{array}$ & $\begin{array}{c}\text { Power Payback } \\
(\mathbf{k W})\end{array}$ & $\begin{array}{c}\text { Power Payback } \\
\text { as Percentage of } \\
\text { Reserve } \\
\text { Capacity (\%) }\end{array}$ & $\begin{array}{c}\text { Percentage Increase } \\
\text { in Daily Peak Load } \\
(\%)\end{array}$ \\
\hline 0 & 76.3 & $15 \%$ & $5 \%$ \\
\hline 150 & 43.6 & $9 \%$ & $1 \%$ \\
\hline 300 & 53.2 & $11 \%$ & $2 \%$ \\
\hline 600 & 63.1 & $13 \%$ & $3 \%$ \\
\hline
\end{tabular}

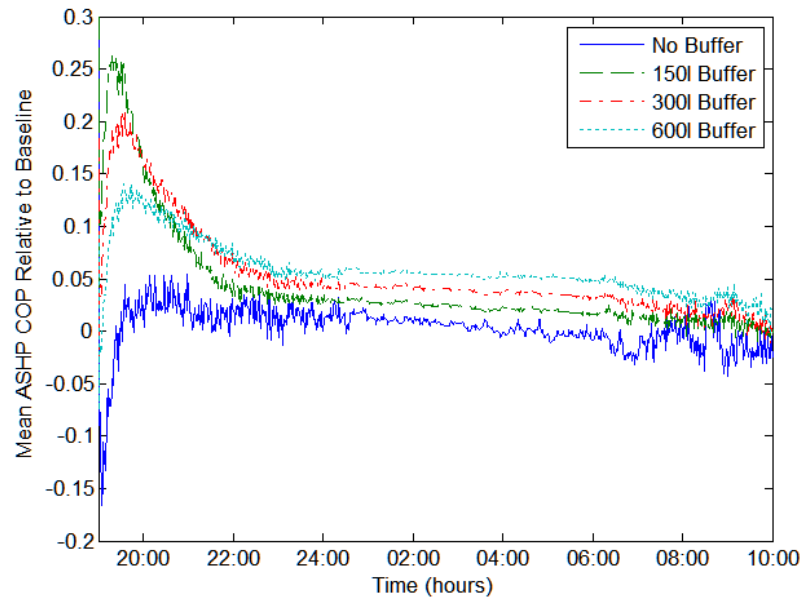

Figure 7. Mean ASHP COP relative to the baseline vs time

\section{2) Comfort}

Figure 8 shows the mean average inside air temperature relative to the baseline for all cases. As the buffer volume increases the maximum average comfort loss diminishes, since there is greater thermal inertia in the system to maintain temperature during ASHP curtailment. However, the marginal benefit associated with buffer volume reduces as the buffer volume increases. For example, a 1501 buffer causes a $0.1^{\circ} \mathrm{C}$ reduction in maximum average temperature compared with the no buffer case, whilst a 6001 buffer only adds an extra $0.07^{\circ} \mathrm{C}$ reduction to the 1501 case. Larger buffers are better at maintaining inside temperature because they are able to supply more heat to the building during ASHP curtailment. However, as the size of the buffer increases so does the delay in recovery 
of indoor temperature. For example, the no buffer, 1501, 3001 and 6001 cases take approximately 1 hour (20:00), 2 hours (21:00), 3 hours (22:00) and 4 hours (23:00) to begin recovering inside temperature respectively. This is a result of the buffer requiring recharging following the reserve period, illustrating how systems with very large buffers may be less responsive that systems with smaller buffers.

Figure 9 shows the number of houses with inside temperature relative to the baseline less than $-0.5^{\circ} \mathrm{C}$. Like the previous case, it can be seen that only the non-buffer case exhibits temperature deviation greater than this limit, with an uneven distribution of houses around the mean, caused by the same phenomena as discussed previously.

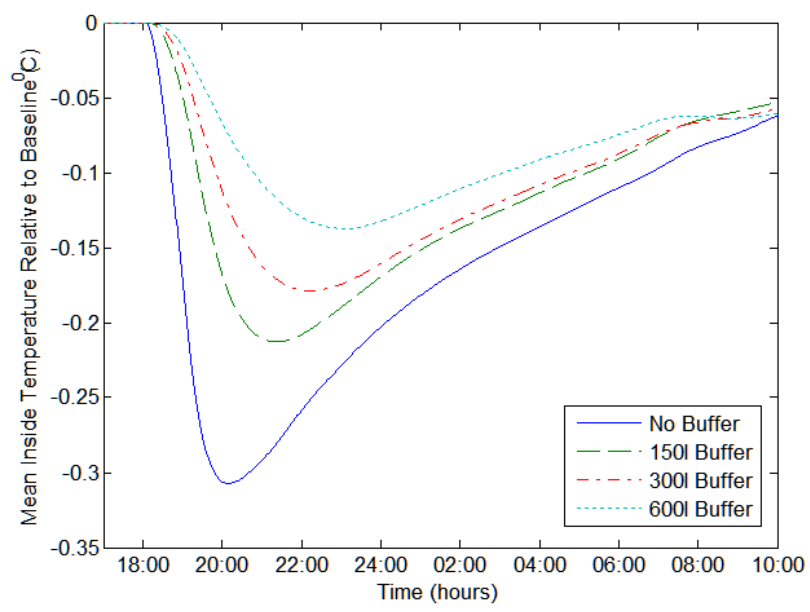

Figure 8. Mean inside temperature relative to the baseline vs time

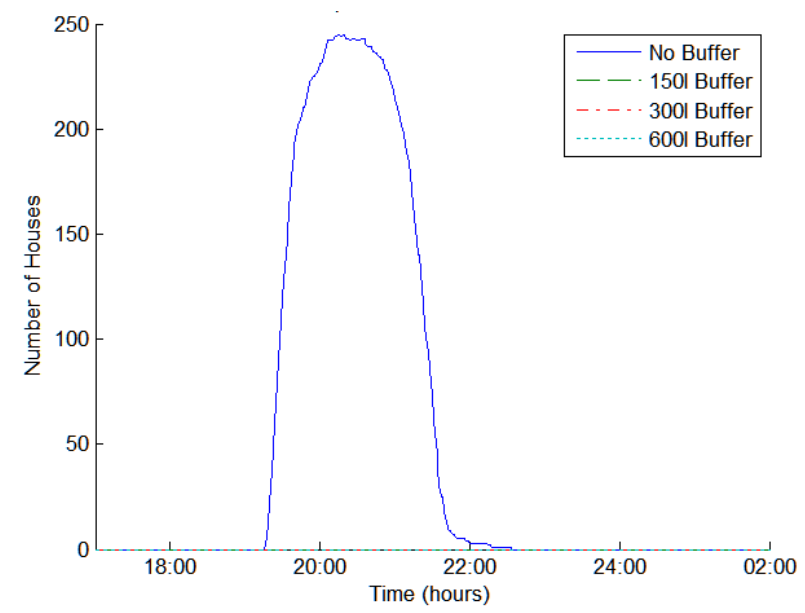

Figure 9. Number of houses with inside temperature relative to the baseline below $-0.5^{\circ} \mathrm{C}$ vs time

\section{CONCLUSION}

This paper describes a methodology to model flexibility for ETTs and measure the impact on comfort and power payback. This has been demonstrated by modelling a cluster of 500 domestic ASHP units. Results show the curtailment of ASHPs causes only a small increase in aggregated peak power consumption, since the diversity factor of ASHP loads is already close to one under extreme cold conditions without curtailment. The introduction of a buffer has been shown to reduce power payback slightly, although large buffers reduce power payback less than smaller ones. The impact on occupant comfort increases with reserve capacity, although such impacts may be reduced by incorporating a buffer, with larger buffers causing the greatest benefit in terms of comfort loss. This research may be developed further by exploring the behaviour of heating system elements in more depth to better understand the identified phenomena. Additionally, the methodology may be extended to other ETT such as Combined Heat and Power (CHP) units.

\section{REFERENCES}

[1] D. Six, J. Desmedt, D. Vahnoudt, and J. Bael, "Exploring the flexibility potential of residental heat pumps combined with thermal energy storage for smart grids," C I R E D 21st Int. Conf. Electr. Distrib. Frankfurt, 6-9 June 2011, no. 0442, 2011.

[2] U. I. Dar, I. Sartori, L. Georges, and V. Novakovic, "Advanced control of heat pumps for improved flexibility of Net-ZEB towards the grid," Energy Build., vol. 69, pp. 74-84, 2014.

[3] J. Hong, N. J. Kelly, I. Richardson, and M. Thomson, "Assessing heat pumps as flexible load," Proc. Inst. Mech. Eng. Part A J. Power Energy, vol. 227, no. 1, pp. 30-42, 2012.

[4] P. MacDougall, B. Roossien, C. Warmer, and K. Kok, "Quantifying flexibility for smart grid services," IEEE Power Energy Soc. Gen. Meet., pp. 1-5, 2013.

[5] N. J. Kelly, P. G. Tuohy, and A. D. Hawkes, "Performance assessment of tariff-based air source heat pump load shifting in a UK detached dwelling featuring phase change-enhanced buffering," Applied Thermal Engineering, vol. 71, no. 2, Elsevier Ltd, pp. 809-820, 2014.

[6] A. Navarro-espinosa, N. Good, L. Zhang, P. Mancarella, and L. F. Ochoa, "EHP in Low Voltage Networks : Understanding the Effects of Heat Emitters and Room Temperatures," in IEEE PES PowerTech 2015,2015

[7] N. Good, E. A. Martínez Ceseña, L. Zhang, and P. Mancarella, "Techno-economic and business case assessment of low carbon technologies in distributed multi-energy systems," Appl. Energy, Oct. 2015.

[8] L. Zhang, N. Good, A. Navarro-Espinosa, and P. Mancarella, "Modelling of Household Electro-Thermal Technologies for Demand Response Applications," IEEE ISGT Eur. 2014, pp. 1-6, 2014.

[9] N. Good, L. Zhang, A. Navarro-Espinosa, and P. Mancarella, "Physical modeling of electro-thermal domestic heating systems with quantification of economic and environmental costs," in Eurocon 2013, 2013, no. July, pp. 1164-1171.

[10] N. Good, L. Zhang, A. Navarro-espinosa, and P. Mancarella, "High resolution modelling of multi-energy domestic demand profiles," Appl. Energy, vol. 137, pp. 193-210, Jan. 2015.

[11] E. Ela, M. Milligan, and B. Kirby, "Operating Reserves and Variable Generation," 2011.

[12] Kensa Engineering Ltd, "How COP varies with Inlet and Outlet Temperature," 2009.

[13] BSI, "BS EN14511-2:2013 Air conditioners, liquid chilling packages and heat pumps with electrically driven compressors for space heating and cooling." British Standard Institution, 2013.

[14] Climaveneta, “AWR_DHW2_XE_0021-0101_201111_EN." 2011.

[15] A. Navarro-Espinosa and P. Mancarella, "Probabilistic modeling and assessment of the impact of electric heat pumps on low voltage distribution networks," Appl. Energy, vol. 127, pp. 249-266, Aug. 2014.

[16] S. Park, Y. Jin, and Y. Yoon, "Designing a Profit-Maximizing Critical Peak Pricing Scheme Considering the Payback Phenomenon," Energies, vol. 8, no. 10, pp. 11363-11379, 2015.

[17] P. Dunbabin, H. Charlick, and R. Green, "Detailed analysis from the second phase of the Energy Saving Trust's heat pump field trial," no. May, 2013. 